\title{
Implementation of the National Media Commission's Guidelines for Local Language Broadcasting, a conduit for local language media accountability in Ghana
}

\author{
Caroline Aboagye Da-Costa \\ Christian Service University College, Kumasi, Ghana
}

Fausta Kilian Ganaa

Director of Public Affairs, Accra Technical University, Accra, Ghana;

Asuamah Adade-Yeboah

Christian Service University College, Kumasi, Ghana

\begin{abstract}
Broadcasting in the local language in Ghana, especially on radio, has come under stakeholder criticisms over years. The National Media Commission (NMC), Ghana's independent media regulator introduced the Guidelines for Local Language Broadcasting (GLLB) in 2009 as a counterweight to guide the reputation of local language broadcasting. Ten years down the line, the criticisms continue against a backdrop of NMC's failure to make its impact felt and not being effective in popularizing the GLLB among the local language media fraternity. Using interviews, observations and content analyses of the GLLB, the study enhances the GLLB's implementation by local language radio stations in Ghana with all the perceived challenges. The study found out that for the GLLB to be effectively implemented, the NMC needs an elevation to the status of an Authority in order to command enormous power to exercise. The tenets of the GLLB also need to be re-visited and revised from a Guideline into a Standard, after consultations with the relevant stakeholders.
\end{abstract}

Keywords: Ghana; Guidelines for Local Language Broadcasting; media accountability; National Media Commission; Local language broadcasting.

\section{INTRODUCTION}

In 2009, the National Media Commission (NMC), Ghana's independent media regulator, with financial and technical support from the United Nations Development Programme (UNDP), introduced the Guidelines for Local Language Broadcasting (GLLB). It is a language-use document established with the objective to "distil research in journalism, linguistics, translation and media ethics by providing practical suggestions and guidance for improving local language broadcasting" [1]. It is segmented under five headings - ethical broadcasting, local language news broadcasting, local language programming, election related issues in local language broadcasting and issues of conflict of interest [1]. This document was meant to guide the credibility of broadcast stations which 
Da-Costa, C. A., Ganaa, F. K., \& Adade-Yeboah, A. (2020) Implementation of the National Media Commission's Guidelines for Local Language Broadcasting, a conduit for local language media accountability in Ghana. Advances in Social Sciences Research Journal, 7(4) 373-386.

operated extensively in the local language and at the time had been accused of ethical violations and lowered professional standards. These local languages FM stations (most of them operating in the Akan language) used language considered intemperate in the Akan culture [2] and so they had attracted a lot of criticisms. The GLLB was introduced as a counterweight for such infractions, among others and also to introduce some level of decorum to the local language broadcasting space.

Ten years after its introduction, however, media performance and results in light of set targets in the GLLB have not been achieved, thus, concerns around the lack of professionalism that the GLLB sought to address persist [3]. Particular among the critics, over the years, have been the Media Foundation for West Africa [4], some radio audiences [5], media scholars [3][6][7] and the NMC, which is the media regulator that introduced the GLLB [8][9][10]. These concerns persist because majority of the local language broadcast stations are not implementing the provisions in the GLLB and the media regulator has not made its presence felt in the industry.

The objective of this paper is to illuminate the perceived challenges and the prospects of getting the GLLB implemented by local language broadcast media houses. The paper subsequently argues that, there is a need for stakeholder consensus in crafting the GLLB with specific implementation modalities for an upgrade into a standard or policy for mandatory implementation. Finally, the study also argues that the NMC needs to be elevated from a Commission to an Authority to be able to sanction defaulting local language FM stations.

\section{LOCAL LANGUAGE RADIO IN GHANA}

Radio broadcasting in Ghana started in the English language. It was introduced in the then Gold Coast in the 1930s by the British colonial administration. The adoption of the ex-colonial language, English as official language for Ghana after independence affected the language of broadcasting to the extent that even after the colonial administration had left, all FM radio stations in the country were broadcasting in the English language irrespective of the fact that majority of the population were illiterates, hence marginalised. The local people could not benefit from the media which was considered "a crucial tool for information dissemination, public discussion and debate, communication of social thought, as well as a means to challenge and legitimise governments" [11]. However, the liberal and democratic reforms on the continent of Africa in the 1990s, of which Ghana was not left out, saw the emergence of competitive, independent and pluralistic radio programming with diversity of languages [12]. In Ghana, for instance, Blankson [12] notes that this new wave spiralled into the use of five local languages on radio, including Twi, Ewe, Hausa, Ga and Dagbani. This was applauded by broadcasting audiences because the literacy level at the time was low and access to the mass print media was limited. The general accessibility of local language radio has brought radio close to the people, because they are able to identify with it. Salawu [13] has argued that local language media, especially radio, has become an efficient tool in popularising the use and the learning of African languages. This has augmented their roles as avenues for development, teaching and the significance of preservation of indigenous languages and culture [6][12]. Their importance makes it imperative for broadcasters to use local languages to educate, inform and entertain the societies they serve.

With the passing of time, trends have changed. Local language radio is now in vogue and has come to stay. About two-thirds of all FM stations in Ghana now broadcast in local languages, majority of them in the Akan language. A great deal of people, both literate and illiterate, now depends on the 
local language radio as their main source of information. This notwithstanding, their activities have greatly come under criticism. Criticising the language and style of Akan news presentation, for instance, Sakzeesi [14] opines that "the introduction of Akan Stations have seriously dented MultiMedia's image in the Broadcast Media landscape". The Akan language, and indeed Ghanaian languages generally, culturally frown on the public use of profane, vulgar and intemperate language use by individuals, more so in the mass media. Yankah [15] confirms this by opining that "the perceived power of the spoken word among Akans call for the deployment of various strategies of speaking that may obviate crises. These include avoidance or discretionary uses of verbal taboos, apologizing for their use, using euphemisms or resorting to indirection". The future of local language broadcasting in Ghana is glowing and efforts at nourishing their activities to make them worthy of existence need to be sustained.

\section{THE NEED FOR ACCOUNTABILITY IN THE MEDIA}

The media in most countries serve to 'police' political governments to be accountable to the people they serve but are the media themselves accountable and to whom? The media's quest for freedom, on the one hand, and the government and society's quest for media responsibility, on the other hand, often breeds some kind of tension when issues of media accountability are raised. McQuail [16] argues that media accountability includes "all the voluntary or involuntary processes by which the media answer directly or indirectly to their society for the quality and/or consequences of their publications". Governments, media regulators, stakeholders and society at large often have some expectations of the media. These expectations may be in written form or not, but whichever form expectations take, the performance of the media is measured against the set expectations and if performance does not match expectations, there is tension. When the results achieved after an activity are measured against the set standards, performance accountability is being undertaken. The media's quest to do what pleases them and their audiences may not necessarily be in agreement with performance standards set by media regulators and this can create serious hitches between the media and their regulators. Plaisance [17] argues that this tension often has to be managed rather than to be solved. No matter the freedom enjoyed by the media, because they do not work in a vacuum but in a society, they have an obligation to the society within which they work. This obligation, therefore, requires the media to operate in a way that enhances, rather than jeopardises society [18].

The locus of accountability - vertical or horizontal - often determines the type of accountability demanded. Vertical accountability emanates from an external source, while horizontal accountability has to do with internal demands or accountability demanded from within a professional organisation or institution. McQuail [19] identifies that the responsibilities and obligations of the media could be assigned, contracted or self-chosen. The type of accountability demanded often depends on the sources of the responsibilities given and these responsibilities come with varying degrees of obligations based on set criteria. Thus, the one imposing the responsibility determines the accountability criteria or what should be done, as well as the urgency and frequency of those criteria. Accountability criteria should be clear and concise enough to avoid ambiguity. There should also be an evaluation carried out at periodic intervals so as to find out if the responsibilities are being executed to meet the set standards. Where necessary, commensurate sanctions should be applied when the accounting actors fail to discharge their responsibilities as expected and there should also be commendation when the standards are met. 
Da-Costa, C. A., Ganaa, F. K., \& Adade-Yeboah, A. (2020) Implementation of the National Media Commission's Guidelines for Local Language Broadcasting, a conduit for local language media accountability in Ghana. Advances in Social Sciences Research Journal, 7(4) 373-386.

Schedler [20] identifies two dimensions to the concept of accountability. These dimensions are answerability and enforcement. Answerability implies "stewardship and the obligation to justify one's actions and decisions in a role" [21]. Broadcasters are assigned various roles whether on air or in editorial and each action contributes to media performance. Regardless of the decisions taken or choices made, people assigned specific roles should be in a position to justify their actions when accountability is demanded. The other aspect of accountability is enforcement [20]. Enforcement implies applying sanctions in the event that the 'steward' failed to discharge responsibilities or account for their decisions and actions to meet the standards set. This calls for a roll-out of practical enforcement modalities with attainable targets.

\section{DISTINCTION BETWEEN POLICIES, STANDARDS AND GUIDELINES}

Policies, standards and guidelines are related and there is often a temptation to interchange them when one is not sure of their features or when the type of document is not clearly stated. With this in mind, the following definitions and descriptive features are worth knowing. A policy provides emphasis, sets direction and is signed by a recognised management body or authority (Certified Information Systems Auditors (CISA)[22]. Policies constitute the highest level of regulatory document, which have legal backing and are often enforced to ensure mandatory implementation by stakeholders. Provisions in policies are broad in their outlook and do not specify step-by-step procedures for adherence [23]. Standards are mid-level documents whose applications are higher in application than guidelines, but lower than policies. They provide a uniform method to policies and the application of a standard is mandatory. Guidelines, on the other hand, are made up of strongly recommended, non-mandatory controls. They usually include best practice that serve as a reference or information that fills in gaps when there is no applicable standard [23]. Guidelines put together "how-to-do-it' - recipes" [24] or step by step ways of applying standards and policies. CISA [22] states that guidelines can be used to create a new standard, where the situation demands.

\section{Implementation of Guidelines}

Literature on media guidelines implementation strategies is non-existent, essentially because guidelines are considered recommendatory and so they have discretionary usage. But every management body that institutes guideline does so with the aim of getting it implemented. In a work setting, where guidelines have been established to superintendent daily activities and actions, there is a need to work within the confines of those guidelines. Bustelo [24] argues that guidelines "regulate professional practice" within different fields. Guidelines are established to give direction on how to achieve broad policy issues that are outlined in policies and standards, thus, when a broad policy is issued, an attendant guideline will then be issued to provide the step-by-step processes required to achieve the provisions in the policy.

Guidelines may not have legal backing but represent the state-of-the-art practices [25], in that they are designed after careful research, based on years of past experience, as well as expert knowledge. Hence, though they are not statutory and as such recommendatory, they can serve as reference and assist legislators in issues of regulation. Schwartz, et al [25], put forward that associational and societal guidelines are often written and peer reviewed by recognised experts, thus, increasing the legal significance of guidelines. Damen, et al[26] also contend that guidelines do not have direct legal status but have gained indirect legal significance. They note that in the Netherlands, the Supreme Court ruled in March 2001 that not following a medical guideline or protocol could be judged as an answerable shortcoming. In the European context, Bustelo [24] notes that, evaluation guidelines 
have been approved by the evaluation societies of France, Germany, Switzerland and the United Kingdom and, thus, have legal backing which makes implementation highly recommended.

Bustelo [24] argues that some guidelines are very general, while others are specific. Specific guidelines, he notes, are concerned with defining quality and, therefore, they provide more specific and concrete actions on the best ways to undertake an activity. As suggested by Schwartz, et al. [25], such specific guidelines can serve legislators in the regulation and arbitration of difficult professional cases and so they must be implemented.

Based on the foregoing, this section will attempt to equate policy implementation with guidelines implementation on the backdrop that guidelines could stand alone and fill in gaps when there is no applicable standard or policy [23]. This section will draw on public policy implementation strategies to review some literature on media policies that were implemented in some countries.

Implementation is viewed as the process of interactions between setting goals or policy intent and the actions taken towards achieving set goals or outcomes [27]. Thus, studies on implementation stress the need to understand factors that affect the success or failure of policies. In light of the fact that various preconceptions have shaped various models of policy implementation [28], the implementation of the GLLB will be discussed in the light of the two overriding models of public policy implementation - the classical and the integrationist models [29]. The classical model views policy making and implementation as two distinct entities which are bounded and sequential with a clear division of policy makers (policy deciders) and policy implementers. Nakamura and Smallwood [28] note that the policy process in the classical model is chronological where policy making always precedes implementation. This model has been criticised as a top-down approach that regards policy as "given and seeks to explain what is right or wrong with the implementation process and with the institutions responsible for implementation rather than the policy itself" [29]. The integrationist model on the other hand integrates the interests of policy makers and policy implementers as the two major actors of a policy, thus, policy making and policy implementation are inextricably linked. In this model the fine line between policy makers and policy implementers dissipates and in the process issues of contention are discussed through a process of interpreting, clarifying, advising, and recommending.

For policy implementation to be effective the attendant influencing factors need to be provided. Edwards \& Sharkansky [30] note that "the first requirement for effective implementation is that those responsible for carrying out a decision must know what they are supposed to do. Orders to implement a policy must be ...consistent, clear and accurate..." They further note that the availability of resources is a major booster to effective policy implementation. "No matter how clear the implementation orders are, if the personnel responsible for carrying out policies lack resources to do an effective job, policy makers will be disappointed in the results" [30]. Essential resources could be in the form of control systems and procedures employed to ensure effective implementation of policy. These may include the organisational arrangement; financial resources; recruitment and training of implementers; explicit work methods and procedures with regulations and manuals or codes; control measures in the form of monitoring and evaluation. The following case studies portray how some media policies were implemented: 
Da-Costa, C. A., Ganaa, F. K., \& Adade-Yeboah, A. (2020) Implementation of the National Media Commission's Guidelines for Local Language Broadcasting, a conduit for local language media accountability in Ghana. Advances in Social Sciences Research Journal, 7(4) 373-386.

\section{Case 1}

Nigeria introduced a Communication Policy which regulates the media. Adekoya \& Ajilore [31] attests that there was little or no problem with the communication policy itself and the roles assigned to various media outlets towards the achievement of national development. However, the problem they identified was in the implementation, particularly, the execution of the various roles. Affirming the above assertion and giving further details, Pate, Akinfeleye \& Oso (cited in [32]) opine that the Nigerian Communication Policy was bedevilled with fundamental implementation problems attributed to economic and ethical factors including pervasive corruption, difficult operational climate, urban-centred journalism, weakening government investments, and the failing public sector. While the government and the media fraternity had been blamed for noncommitment in the implementation of the policy in some instances [31][32] others have blamed it on the fact that mass communication professionals and scholars were not involved in the policy formulation [52]. This goes to emphasize that the non-implementation cannot be blamed on one factor. While Pate, Akinfeleye \& Oso (cited in [32]) foresee a solution in the review of the policy and adoption of implementation strategies to take place at the federal, state and local levels, Johnson \& Alao [52] foresee effective implementation in a coherent document as well as an implementation strategy that involve professionals and mass communication scholars. Pate, Akinfeleye \& Oso (cited in [32]) on the other hand suggest the involvement of stakeholders such as the private sector and civil society to carry out research and measurement of effectiveness.

\section{Case 2}

In a Zimbabwean case, Mabika \& Salawu [33] attest that the Broadcasting Services Amendment Act which had guidelines of implementation incorporated into its formulation had been challenged with implementation issues. They note that the Act which was supposed to be implemented by all broadcasting stations seems to be a burden only of indigenous language radio broadcasting services since it places restrictions on them in their programming content, thus, their programmes do not seem to be attractive and competitive. English language stations, they corroborate, have been spared in that regard. Secondly, the act seems to have singled out and enumerated guidelines for public broadcasters to implement but private stations, though guided by the same Act do not adhere to the Act on the ticket that no guidelines had been attributed to them [33]. The effect of the implementation of this 'unfair' Act has seen minority indigenous languages been used less, thus the risk of extinction.

\section{METHOD}

The study was born out of a broad research at the University of South Africa. The study was based on a two months extensive study of broadcast practitioners in Hello FM, a local language broadcast station in Kumasi in the Ashanti Region of Ghana, from July to August 2017. It adopted a qualitative approach employing both primary and secondary data sources. Primary data was gathered through semi-structured interviews and direct observation. Semi-structured interviews were held with the heads of unit in the news department, thus, the News Editor (NE), Head of Newscast (HNC), Head of News Research (HNRH) and Head of News Report (HNR). Additionally, overt observations of the day-to-day activities of newsroom staff were conducted. Interview and observation schedules were prepared based on the objectives of the study by considering the staffing situation; resources and facilities as well as the institutional arrangements available in Hello FM for implementation of the GLLB. Semi-structured interview data was analysed using thematic analysis and the observation data was analysed using text summaries. Secondary data for the study was obtained from Chapter 
two of the GLLB, which deals essentially with local language news. The analysis of the contents of the GLLB was done through textual analysis. The research was undertaken upon approval and clearance by the Ethics Board of the Department of Communications at the University of South Africa.

\section{DISCUSSIONS}

This section triangulates the findings in a composite fashion by not strictly distinguishing between data received from the various instruments.

\section{Visibility of the National Media Commission}

The National Media Commission, being the independent media regulator in Ghana is vested with the responsibility of registering, regulating and monitoring the activities of media houses in Ghana. However, their presence is hardly felt by the media fraternity in Ghana [3][5][7]. With two offices in Accra (to service the southern sector) and Kumasi (to service the northern sector), their presence seems unfelt by media practitioners. During the interview session, the heads of units at Hello FM knew about the existence of the NMC as media regulator but did not know the location of their office which was just about a kilometre from their FM station, let alone to know about their regulations. They also perceived the NMC as inactive. The Head of Newscast and the News Editor, for instance assert that:

The NMC is very inactive. I have not seen the government or the NMC putting any pressure on the media in Ghana. Because if they do, you wouldn't find what you find these days. A lot of FM stations do whatever they want. Some of the casters over emphasise. I think if they enforce the rules and regulations, we won't have this. [HNC]

I think that the NMC is not authoritative enough and so more powers can be given to the $N M C$ so that they can "bite" because I don't think the NMC has that prosecutor powers to prosecute radio stations or media houses that goes against the Guidelines. I don't think that they have that kind of power so like advising and probably cautioning, that is what they do. [NE]

These finding corresponded with findings by Opare-Henaku [7] and Nyavor [5] in separate studies conducted in the newsroom of Adom FM in the Greater Accra Region of Ghana. Research suggests that the Ghana Journalists Association (GJA), which is the media umbrella of all journalists in Ghana seemed more popular than the NMC [3] [34].

The NMC's regulation mandate seems to be on low key. Various instruments have been designed by the NMC including the National Media Policy and the Broadcasting Standard which have mandatory implementation as well as the GLLB but defaulters often do not get punished but rather advised or cautioned. A point in reference is when the NMC was petitioned by some broadcasters on the issue of three television stations in Ghana (TV XYZ, Thunder TV and Ice TV) broadcasting pornographic content on free-to-air television. The petitioners noted that the action of the TV stations was against Section 7 (e) of the NMC Broadcasting Guidelines provision which states that "Actual sexual intercourse between humans should at no time be transmitted." In response, the NMC noted that the actions of the television stations were against the Broadcasting Standards, however, due to the limitations of the NMC in sanctioning, the stations were barred from airing such content and were only cautioned against such practices [35][36]. Per its constitutional mandate, the NMC's powers to 
Da-Costa, C. A., Ganaa, F. K., \& Adade-Yeboah, A. (2020) Implementation of the National Media Commission's Guidelines for Local Language Broadcasting, a conduit for local language media accountability in Ghana. Advances in Social Sciences Research Journal, 7(4) 373-386.

sanction media houses and media practitioners that default in set regulation targets are weak. A study by the World Bank Group [37]. indicated that "The NMC's powers for regulating content and settlement of complaints are not sufficient to deal with content-based problems" like what the GLLB was meant to deal with. They have no authority to punish offenders but to ask for retraction of offending publications or request for apology on behalf of affected individuals or media houses. Stakeholders in the media industry perceive that the NMC has not lived up to expectations regarding their mission [21] and even media practitioners do not have confidence in them [34]. This explains the numerous complains about media performance in Ghana [2][4][6][14][38][39][40][41]. The NMC has consistently been criticised for paying lip service to media accountability standards in Ghana, thus, impacting negatively on its reputation. Tettey [21] notes that the failure on the part of monitoring institutions to perform their watchdog role could damage their reputation and affect their credibility as well. This is the current fate of the NMC.

There have been concerns about the need to give enormous powers of exercise to the NMC by revising the Act of Parliament that constituted it. The World Bank Group [37] made a recommendation to the effect that "Amendments should be made to the National Media Commission Act to strengthen its powers of sanction and to provide for a formal appeals process in relation to $\mathrm{NMC}$ rulings on complaints" but this is yet to see the light of day.

\section{The GLLB as "ideal model" for regulating local language media in Ghana?}

The GLLB was introduced in 2009 by the media regulator in Ghana. It serves as a benchmark to ensure that local language broadcast media in Ghana maintained good standards of practice in the discharge of their duties, by prescribing rules of what should and what should not be done. The provisions are presented in positive terms for actors in the local language broadcasting scene to "adopt, cultivate and apply journalistic practices that are in sync with Ghanaian normative expectations regarding the media's institutional, legal and informative function" [42]. Apart from giving the normative direction of what the media regulator expects of local language broadcast stations in Ghana, one wonders if it could stand the test of being the "ideal model" to proffer what local language broadcasting should be in Ghana [16], by being accepted by all and sundry? Indeed, every society has expectations of what its institutions, the media inclusive, should be and, as such, lays out measures of achievement, to benefit the larger society. But, like Hallin \& Manchini [43] argue, normative documents in communication and journalism need to prescribe rules determining how things should be done rather than limiting itself to what is happening. They should provide a yardstick against which media performance, accountability and quality could be measured and possibly controlled [44]. The GLLB in its current state lacks this impetus. It was introduced to solve an existing problem but its tenets cannot be used to hold local media accountable for any infractions. The media regulator has again not done due diligence in popularizing the document among the media fraternity. The study revealed a situation where people at the helm of affairs in Hello FM which is considered the 'best' and most popular FM station in the Ashanti Region of Ghana [45][46][47][48] were not aware of the GLLB. The Head of News Research for instance notes that:

Not really, I don't know about the NMC'S GLLB. I have not seen a copy before and I have not read it. [HNRH]

The zeal that accompanied the launch of the document in 2009 faded with the glamour of the occasion. Implementation and monitoring has just like Mpofu and Mutasa [11] attest, been faced with a "half-hearted and non-committal approach to planning and policy making on the language 
issue". If journalists are not aware of what is expected of them, how could they achieve it? Secondly, it was found out that broadcasters were not consulted in the formulation of the GLLB. For some broadcasters in Hello FM who had been in the media industry for over sixteen years not to be aware of the GLLB, suggests that the media's participation in formulating the GLLB was either minimal or non-existent. The formulation of the GLLB, as noted in the foreword, is suggestive of consultations with broadcast media practitioners, but research has proved otherwise. Broadcasters at Hello FM were not consulted in the formulation of the GLLB and this finding corroborates with that of OpareHenaku [7] in the newsroom of Adom FM.

Since the broadcasters at Hello FM were not aware of the GLLB, sections that pertained to their work were read to them. Generally, they found the tenets of the GLLB to be good for implementation. The Head of Newscast, for instance, noted that:

Yes, I think from the excerpts read to me, we need to comply with the NMC's GLLB. And then also, they should hammer it and they should make it available. They should let us be aware. The organisation, the government, in this case, the NMC, should have periodic training for both radio owners and journalists. They should have it because if the owners are trained or if they are well oriented on the rules, the regulations and other things, they will transfer it to their workers. They will ensure that the workers are also doing it but, in this case, I don't even think most of the owners are aware or they are aware but because the NMC is not enforcing it, they are also ignoring it. So periodically, I think something should be done about it. [HNC]

The heads of units were, however, unanimous in affirming that sub-section 2.3.5, which stipulates that "as far as is practicable, local language news must be gathered and presented in the language intended for broadcasting", was non-implementable. Their claims were based on the assertions that there was the lack of resources for translation, like Twi dictionary and publications by the Bureau of Ghana Language, which the GLLB recommends. Again, they asserted that translating from English to Akan would require a lot of words which would translate into cumbersome scripts since some English words did not have corresponding words in the local language, hence requiring phrases and sentences to explain. The Head of News Research aptly explain as follows:

Well, let me say, it's not a bad idea butyou see, when you transcribe in Twi, for instance, when a script is given to you in English and you are transcribing in Twi, you require a lot of words to put together before you can get it. So, I think this particular policy has to be reviewed. Because translating such words into Twi makes it very difficult for the translator or so but when reading, to my understanding, reading the news depends on your understanding so when a story is given to the news reader, the news reader must understand it well before the person can present it to the audience, so honestly, I must say, it will be challenging. [HNRH]

This finding supports the position of broadcasters in Adom FM who considered the general provisions of the GLLB to be out of date [5][7].

The GLLB needs to be clear on implementation strategies for goal achievement. Edwards \& Sharkansky [30] opine that orders for implementation of policies should be "consistent, clear and accurate in specifying the aims of the decision-makers." Just as Pate, Akinfeleye \& Oso (cited in [32]) have called for a review of the Communication Policy in Nigeria to include clear implementation 
Da-Costa, C. A., Ganaa, F. K., \& Adade-Yeboah, A. (2020) Implementation of the National Media Commission's Guidelines for Local Language Broadcasting, a conduit for local language media accountability in Ghana. Advances in Social Sciences Research Journal, 7(4) 373-386.

strategies at the federal, state and local levels, the GLLB needs a review with such strategies as well. At the launch in 2009, the NMC emphasized its preparedness to monitor FM stations on the implementation of the GLLB but since the document lacked clear implementation strategies on how recommended resources could be obtained, how targets were to be achieved with deadlines, for instance, broadcasters ignored it and the regulator has not been upbeat in getting the tenets achieved. This emphasises that without clear implementation strategies, there is bound to be policy implementation failure.

For effective formulation, acceptance and implementation of the GLLB, there is a need for consensus building with various stakeholders. Consensus building in matters of rule-formation, especially with those expected to implement them, often ensures greater implementation and compliance. Similar to the Nigerian situation above, there were minimal consultations in formulating the GLLB. The consideration of broadcasting systems in Africa as "civil service" by their governments (and government institutions), often leads to a system in which governments speak to rather than engage in dialogue [49] with the broadcasting firms. Coming from the background in Africa where the media was used as a mouthpiece of governments, the media are often seen as propaganda instruments for use by governments in rolling out their plans. These have often led to government's dictating what the media should do and the media in turn fighting back for independence from government control in all spheres. In introducing regulations, if the regulator and government in general want to achieve maximum implementation, there is the need to have dialogue with stakeholders. This is especially true of the implementing body to provide practical inputs in planning. There is also a need for explicit implementation modalities to be laid out and then effective monitoring procedures to ensure effective implementation and, where necessary, amendments should be made. However, if these procedures are not followed, rolling out regulations would be seen as an imposition and will be met with antagonism on the part of implementers, as in the case of the GLLB. As a consequence, if consultative revisions are effectively done, the GLLB could be upgraded into a Standard to serve as a model instrument that could demand accountability from the local language broadcast media practitioners in response to Ugangu [50] and Hodges' [51] call for rules that determined what the press was responsible for.

\section{Model for implementation of the GLLB}

Findings from the interview of unit heads at Hello FM indicated that they were not aware of the GLLB, indicating that the NMC had not been upbeat in promoting the document. Without information, broadcasters cannot know what they are to do. This confirms Edwards and Sharkansky's [30] assertion that "the first requirement for effective implementation is that those responsible for carrying out a decision must know what they are supposed to do". The study proposes that after consultative revisions of the GLLB, the NMC should make itself visible by taking it to the door steps of media practitioners. The study proposes the model below as a measure to ensure effective implementation of the GLLB. 


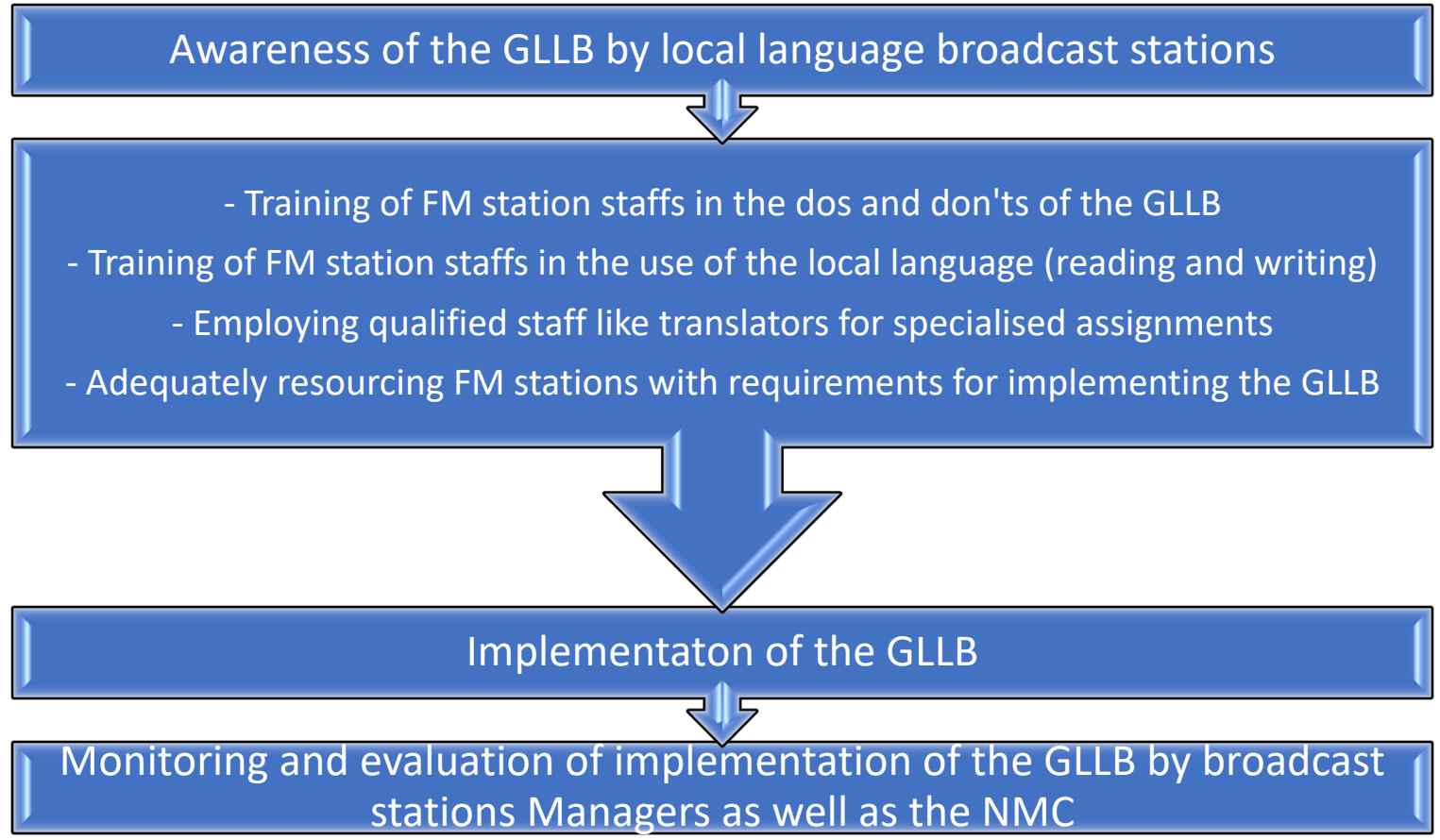

Source: Authors' concept

Figure 1: Model for implementation of the GLLB

\section{CONCLUSION}

From the foregoing, it is evident that local language broadcasting in Ghana has come to stay. And, given the constitutional mandate of the media regulator in Ghana, it has been difficult to get its regulations to be implemented and as such, the picture has been painted as if the media regulator is not up to the task. The study recommends for the status of the media regulator to be upgraded from a commission into an Authority, hence National Media Authority to give it enormous powers to exercise or sanction defaulting broadcasters and broadcast institutions. Further, the Guidelines for Local Language Broadcasting (GLLB) by all standards has merits that can help improve the local language broadcasting space in Ghana, however, the expected implementers have not been made aware of its existence. Additionally, even if they were aware of its existence, the mode of formulation seems imposing and as such the media practitioners do not see the need to implement aspects of it. The paper has recommended for consultative engagements in revising the guidelines and possibly an upgrade into a standard to ensure effective implementation.

\section{References}

[1]. National Media Commission, Guidelines for local language broadcasting, 2009, Accra: Government Printer.

[2]. Antwi Fordjour, E., Foul language in the Ghanaian electronic media: a case study of some selected radio stations in Kumasi, Ghana, International Conference on Management, Communication and Technology, (ICMCT), 2016. IV (1): p. 26-32.

[3]. Aboagye Da-Costa, C., Institutional assessment of the implementation of the National Media Commission's Guidelines for Local Language Broadcasting in local language news in Ghana: A case study of Hello FM [Unpublished masters' dissertation], 2018, University of South Africa.

[4]. IREX, Media sustainability index 2009 on Ghana, 2010.

https://www.irex.org/sites/default/files/pdf/media-sustainability-index-africa-2009-ghana.pdf 
Da-Costa, C. A., Ganaa, F. K., \& Adade-Yeboah, A. (2020) Implementation of the National Media Commission's Guidelines for Local Language Broadcasting, a conduit for local language media accountability in Ghana. Advances in Social Sciences Research Journal, 7(4) 373-386.

[5]. Nyavor, G.M.K., Impact of Akan radio news presentation on the audience of Adom FM [Bachelor's dissertation, Ghana Institute of Journalism]. 2010.

https://www.scribd.com/doc/46413404/IMPACT-OF-AKAN-RADIO-NEWS-PRESENTATION-ON-THE-AUDIENCE-OFADOM-FM-GHANA

[6]. Kwaw, F.E., Promoting cultural diversity and multilingualism. The International Mother Language Day, 2010. www.natcomreport.com

[7]. Opare-Henaku, J., An exploratory study of news room routines of local and English language radio stations: the case of Adom FM and Joy FM [MPhil dissertation, University of Ghana], 2016.

http://ugspace.ug.edu.gh/handle/123456789/21900

[8]. Apenteng, K.G., NMC vows to curb inflammatory language ahead of polls, 2016a.

http://citifmonline.com/2016/07/11/NMC-vows-to-curb-inflammatorylanguage-ahead-of-polls/

[9]. Apenteng, K.G., NMC vows to sanitise airwaves, (2016b).

http://www.mymetrotv.tv/index.php/news/item/929-nmc-vows-to-sanitiseairwaves

[10]. Kuseh, J., Forum on journalism ethics and local language broadcasting held, (2014).

http://ghanadecides.com/2014/09/forum-on-journalism-ethics-and-locallanguage-broadcasting-held/

[11]. Mpofu, P., \& Mutasa, D.E., Language policy, linguistic hegemony and exclusion in the Zimbabwean print and broadcasting media, South African Journal of African Languages, 2014. 34(2): p. 225-233.

[12]. Blankson, I.B., Negotiating the use of native languages in emerging pluralistic and independent broadcast systems in Africa. African Media Review, 2005. 13(1): p. 1-22.

[13]. Salawu, A., Indigenous language media: a veritable tool for African language learning, Journal of Multicultural Discourses, 2006. 1(1):86-95.

[14]. Sakzeesi, C.M., In the matter of 'lunatism' in multi-media and other media houses, 2015.

https://www.ghanaweb.com/GhanaHomePage/features/In-the-matter-oflunatism-in-multi-media-and-other-mediahouses-383488.

[15]. Yankah, K., Speaking for the chief: Okyeame and the politics of Akan Royal Oratory, 1995. Indiana University

Press

[16]. McQuail, D., McQuail's mass communication theory 5th Edition, 2005. London: Sage.

[17]. Plaisance, P.L., The concept of media accountability reconsidered. Journal of Mass Media Ethics, 2000. 15(4): p. 257-268.

[18]. Siebert, F., Peterson, T., and Schram, W., Four theories of the press: the authoritarian, libertarian, social responsibility, and Soviet communist concepts of what the press should be and do, 1963. Urbana: University of Illinois Press.

[19]. McQuail, D., Media accountability and freedom of publication 2003. Oxford: Oxford University Press.

[20]. Schedler, A., Conceptualizing accountability. In The self-restraining state: power and accountability in new democracies, A. Schedler, L. Diamond \& M. F. Plattner (Eds), 1999. Colo: Lynne Rienner, p. 13-28.

[21]. Tettey, W.J, The politics of media accountability in Africa: an examination of mechanisms and institutions. The International Communication Gazette, 2006. 68(3): p. 229-248.

[22]. Certified Information Systems Auditors (CISA), Understanding policies, standards, guidelines and procedures 2011. http://cisacertified.blogspot.com/2011/04/understanding-policies-standards.html

[23]. What are policies, standards, guidelines and procedures? 2009.

Available at: www.mindfulsecurity.com/2009/02/03/policies-standards-and-guidelines/ 
[24]. Bustelo, M., The potential role of standards and guidelines in the development of an evaluation culture in Spain. Evaluation, 2006. 12(4): p. 437-453.

http://journals.sagepub.com/doi/abs/10.1177/1356389006071291

[25]. Schwartz,P.J., et al., The legal implications of medical guidelines - a taskforce of the European Society of Cardiology, European Heart Journal, 1999. 20: p. 1152-1157

[26]. Damen, J., et al., Legal implications of clinical practice guidelines, Intensive Care Med, 2003. P. 29:3-7.

[27]. Smith, K.B., and Larimer, C.W., The Public Policy Theory Primer, 2009. Philadelphia: Westview Press.

[28]. Nakamura, and Smallwood, F., The politics of policy implementation, 1980. New York: St. Martins.

[29]. Marume, S.B.M., Mutongi, C., and Madziyire, N.C., An analysis of public policy implementation. IOSR Journal of Business Management (IOSR-JBM), 2016. 18(4): p. 86-93.

[30]. Edwards, G.C. \& Shakansky, I., The policy predicament: making and implementing public policy, 1978. San Francisco: W. H. Freeman.

[31]. Adekoya, H.O., and Ajilore, K., Empowering national development in Nigeria through appropriate national communication policy. Singaporean Journal of Business Economics, and Management Studies, 2012. 1(4).

[32]. Suleiman, J., The Media, Implementation of the Nigerian National Communication Policy, and Citizens' Participation in Development. European Scientific Journal, 2018. 14(26): p. 193-215.

[33]. Mabika, M., and Salawu, A., A tale of failure: indigenous language radio broadcasting in Zimbabwe. Mediterranean Journal of Social Sciences, 2014. 5(20): p. 2391-2401.

[34]. Akoto-Bamfo, A.A.A., Assessment of the performance of the National Media Commission (NMC) in promoting media professionalism [Bachelor's Dissertation, Ghana Institute of Journalism]. Academia, 2011.

http://academia.edu/3982205/Assessment_of_the_National_Media_Commission_NMC_in_promoting_media_Professio nalism

[35]. Dadzie, K., NMC bans porn on television stations, 2017.

http://showbiz.citifmonline.com/2017/06/23/nmc-bans-porn-on-televisionstations/

[36]. LiveFMGhana. NMC blocks XYZ TV, ICE TV, others from showing porn, 2017.

http://livefmghana.com/2017/06/23/nmc-blocks-xyz-tv-ice-tv-others-showingporn/

[37]. World Bank Group. Ghana Broadcasting Study: A Report for the Government of Ghana and the World Bank, 2005. http://siteresources.worldbank.org/INTCEERD/Resources/WBIGhanaBroadcasting.pdf

[38]. Daabu, M.A., No more anecdotes in news presentation, 2009.

https://www.modernghana.com/news/231148/1/no-more-anecdotes-in-newspresentation.html

[39]. Nyamnjoh, F.B., West Africa: unprofessional and unethical journalism, 2000.

http://www.fes.de/fulltext/iez/00710a01.html

[40]. Owusu, W. Y., The Ghanaian media landscape: how unethical practices of journalists undermine progress, 2012. Oxford: Oxford University Press.

https://reutersinstitute.politics.ox.ac.uk

[41] Paulitsch, L. and Hummelink, L., The Problems of Journalism in Ghana. Central Press, 2012. http://centralpressnewspaper.blogspot.com/2012/12/journalism-in-ghana.html

[42]. Dzisah, W.S., Book Review: Responsible journalism and the quest for professional standards in Ghana. Ghana Journal of Development Studies, 2016. 13(2): p. 207-211.

[43]. Hallin, D.C., and Mancini, P. Comparing media systems: three models of media and politics, 2004. Cambridge, UK: Cambridge University Press. 
Da-Costa, C. A., Ganaa, F. K., \& Adade-Yeboah, A. (2020) Implementation of the National Media Commission's Guidelines for Local Language Broadcasting, a conduit for local language media accountability in Ghana. Advances in Social Sciences Research Journal, 7(4) 373-386.

[44]. Fourie, P.J., Towards linking normative theory, communication policy and audiences in South Africa Communication Research, 2005. Communication 31(1): p. 17-40.

[45]. Business Ghana. Ghana Q4 2016 Radio \& TV Audience Ratings Report, 2017.

https://www.businessghana.com/site/news/entertainment/140306/Ghana-Q4-2016-Radio-TV-Audience-RatingsReport

[46]. Geopoll, Ghana Quarter 22017 radio \& TV audience ratings report, 2017.

https://knowledge.geopoll.com/ghana-media-measurement-q2-2017-kgmmreport-0-0-0

[47]. Geopoll, Ghana Q1 2017 radio \& TV audience ratings report, 2017.

https://knowledge.geopoll.com/ghana-media-measurement-kgmm-report-0-0

[48]. Ghana Web. Ghana media measurement report: top TV, radio, and print outlets in 2017, 2018.

https://www.ghanaweb.com/GhanaHomePage/NewsArchive/Ghana-Media-Measurement-Report-Top-TV-Radioand-Print-outlets-in-2017-620455

[49]. Tomaseli, K.G., Our Culture vs foreign culture. Gazette, The International Journal for Communication Studies, 2003. 65(6): p. 427-441.

[50]. Ugangu, W., Normative media theory and the rethinking of the role of the Kenyan media in a changing social Economic context. [Doctoral thesis, University of South Africa], 2012.

http://uir.unisa.ac.za/bitstream/handle/10500/8606/thesis_ugangu_w.pdf?sequence=1\&isAllowed=y

[51]. Hodges, L.W. Defining press responsibility: a functional approach, in Responsible journalism. D. Elliott, (Ed.), 1986. CA, Sage: p. 13-31.

[52] Johnson, J., and Alao, D., (2013). Towards a robust communication policy in Nigeria: A discourse analysis. Journal of Research and Development, 2013. 1(2). 